\title{
Inflammatory Undifferentiated Pleomorphic Sarcoma Mimicking Bacteremia in an Elderly Patient: A Case Report
}

\author{
Kazuhiko Hashimoto *(D), Shunji Nishimura, Tomohiko Ito, Naohiro Oka and Masao Akagi \\ Department of Orthopedic Surgery, Kindai University Hospital, Osaka-Sayama City, Osaka 589-8511, Japan; \\ shunnisi@med.kindai.ac.jp (S.N.); tomo0251118zooo@gmail.com (T.I.);n-oka@med.kindai.ac.jp (N.O.); \\ makagi@med.kindai.ac.jp (M.A.) \\ * Correspondence: hazzhiko@med.kindai.ac.jp; Tel.: +81-072-366-0221; Fax: +81-072-366-0206
}

Citation: Hashimoto, K.; Nishimura,

S.; Ito, T.; Oka, N.; Akagi, M.

Inflammatory Undifferentiated Pleomorphic Sarcoma Mimicking Bacteremia in an Elderly Patient: A Case Report. Medicina 2021, 57, 175 https: / / doi.org/10.3390/medicina 57020175

Academic Editor: Timothy Damron Received: 6 January 2021

Accepted: 9 February 2021

Published: 18 February 2021

Publisher's Note: MDPI stays neutral with regard to jurisdictional claims in published maps and institutional affiliations.

Copyright: (c) 2021 by the authors. Licensee MDPI, Basel, Switzerland. This article is an open access article distributed under the terms and conditions of the Creative Commons Attribution (CC BY) license (https:// creativecommons.org/licenses/by/ $4.0 /)$.

\begin{abstract}
Undifferentiated pleomorphic sarcoma (UPS) is major type of soft tissue sarcomas. UPS presenting with inflammation is rare, and its pathophysiology remains unclear. Herein, we report a rare case of UPS with prolonged fever. A 91-year-old female complaining of high fever was referred to our hospital because of a high C-reactive protein (CRP) level of $12.51 \mathrm{mg} / \mathrm{dL}$. She had been experiencing intermittent fevers for approximately 10 years. The fever of unknown origin worsened with time and went into remission with repeated antimicrobial therapy. She also had a mass on her central lower back over the sacral region for 6 years, which showed a gradual increase in size. The blood tests showed that the leukocyte count and neutrophils were $6.51 \times 10^{3} / \mu \mathrm{L}$ and $70.3 \%$, respectively. She had a $10 \times 10 \mathrm{~cm}$ mass on her buttock that showed 2-[fluorine-18] fluoro-2-deoxy-d-glucose (FDG) accumulation on FDG-positron emission tomography-computed tomography examination (standardized uptake value-max value: 5.4). A blood culture examination was performed to rule out bacteremia, however, no bacteria were identified. We then performed a needle biopsy and confirmed the diagnosis of UPS; subsequently, the patient underwent a widemargin resection. A few days after the surgery, her CRP, leukocyte, and neutrophil levels decreased to $0.305 \mathrm{mg} / \mathrm{dL}, 2.83 \times 10^{3} / \mathrm{uL}$, and $50.1 \%$, respectively. This case demonstrated that UPS with inflammation should be treated surgically as soon as possible after ruling out other sources of infection to achieve a favorable prognosis.
\end{abstract}

Keywords: Bacteremia; C-reactive protein; inflammation; interleukin 6; undifferentiated pleomorphic sarcoma

\section{Introduction}

There are numerous histological types of soft tissue sarcomas (STSs), and more than 60 types have been defined [1]. The malignant fibrous histiocytoma (MFH) that is an ordinary STS, was first described in 1964 [2]. MFH is a mesenchymal neoplasm that is anatomically ubiquitous and occurs in all ages [2]. In 2002, the World Health Organization (WHO) classification of STS defined MFH as undifferentiated pleomorphic sarcoma (UPS) [1]. Recently, MFH and UPS associated with inflammation have been reported; however, the details of their pathogenesis remain unknown. [3,4]. Herein, we report a case of UPS with severe inflammation in a very elderly patient.

\section{Case Presentation}

The patient was a 91-year-old woman. She had been experiencing fever of unknown origin intermittently for approximately 10 years. She also had a tumor in the central lower back over the sacral region for 6 years. Recently, during hospitalization in another center, she was being treated with antibiotics and blood infusion for high fever and anemia. However, the fever did not improve, and she was referred to our hospital.

The blood examination revealed C-reactive protein (CRP) level of $12.51 \mathrm{mg} / \mathrm{dL}$, white blood cell count of $6.51 \times 10^{3} / \mathrm{uL}$, and neutrophils at $70.3 \%$ (Table 1 ). 
Table 1. The results of blood examination before the surgical treatment.

\begin{tabular}{|c|c|c|c|}
\hline Item & Value & Lower Limit & Upper Limit \\
\hline CRP (mg/dL) & 12.51 & 0 & 0.14 \\
\hline $\mathrm{Cr}(\mathrm{mg} / \mathrm{dL})$ & 1.28 & 0.46 & 0.79 \\
\hline Alb (g/dL) & 2.1 & 4.1 & 5.1 \\
\hline AST (U/L) & 26 & 13 & 30 \\
\hline ALT (U/L) & 23 & 7 & 23 \\
\hline $\begin{array}{c}\text { Leukocytes }(x \\
\left.10^{3} / \mu \mathrm{L}\right)\end{array}$ & 6.51 & 3.3 & 8.6 \\
\hline $\mathrm{Hb}(\mathrm{g} / \mathrm{dL})$ & 7.9 & 11.6 & 14.8 \\
\hline $\begin{array}{c}\text { PLT } \\
\left(\times 10^{4} / \mathrm{uL}\right)\end{array}$ & 38.0 & 15.8 & 34.8 \\
\hline Neutrophils (\%) & 70.3 & 38 & 77 \\
\hline
\end{tabular}

CRP, C-reactive protein; Cr, creatinine; Alb, Albumin; AST, Aspartate aminotransferase; ALT, Alanine aminotransferase; Hb, Hemoglobin; PLT, Platelet.

We performed a blood culture test that revealed no evidence of bacteremia. Radiography of the chest showed no infiltrative shadow suggestive of pneumonia. Urine culture revealed no evidence of bactereia. The $10 \times 10 \mathrm{~cm}$ tumor mass on her buttock was elastic, hard, and immobile. Magnetic resonance imaging (MRI) showed a low-intensity mass adjacent to the sacrum bone on T1-weighted and low- and high-intensity areas on T2-weighted images (Figure 1a,b, respectively). 2-[fluorine-18] fluoro-2-deoxy-d-glucose (FDG)-positron emission tomography (PET)-computed tomography (CT) examination also revealed the tumor mass on her buttock, for which the standardized uptake value (SUV)-max value was 5.4 (Figure 1c). No suspected metastatic lesions, such as in the lungs, were observed. We then performed a needle biopsy of the buttock tumor. The histology showed an increased amount of spindle cells stained well with atypical nuclei (Figure 1d). Heterozygous cells had darkly stained irregular or oblong heterozygous nuclei and stellate or spindle-shaped cytoplasm (Figure 1d). Immunohistological staining for CDK4, MDM2, S-100, SMA, desmin, HHF-35, myogenin, Myf4, and MyoD1 were also negative (data not shown). Since the differentiation tendency of the tumor proved difficult to determine, the patient was finally diagnosed with UPS based on these histological findings.
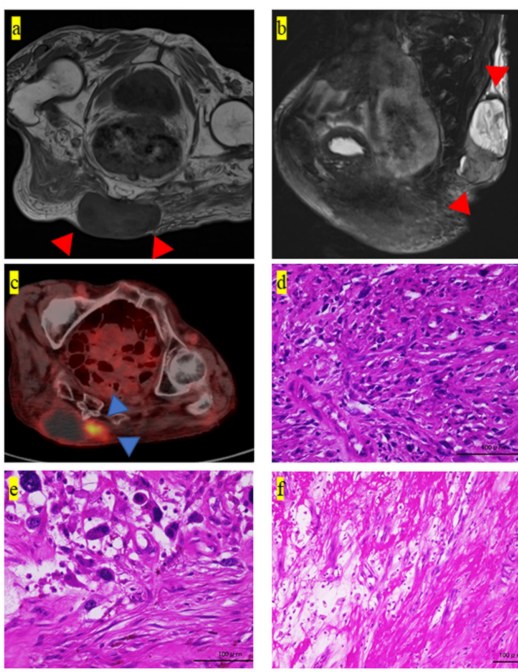

Figure 1. Pathological and imaging findings of the excised tumor. (a) T1-weighted MRI coronal image at the first patient visit. Homogeneous low-intensity tumor mass is observed on the buttock (red arrowheads). (b) T2-weighted MRI sagittal image at the first patient visit. Heterogeneous low- 
and high-intensity areas in the tumor mass are observed (red arrowheads).

(c) $18 \mathrm{~F}-$ fluorodeoxyglucose-positron emission tomography-CT imaging shows heterogeneous accumulation in the tumor (blue arrowheads). (d-f) The pathological findings of the excised specimen. The histology shows (d) increased spindle cells stained well with atypical nuclei, (e) lymphocytes infiltration in the tumor, and (f) lymphocytes infiltration of tumor margins. Scale bar = $100 \mathrm{um}$. MRI, Magnetic resonance imaging; CT, computed tomography.

Subsequently, the patient underwent wide-margin resection. The surgical margin of the resected specimen was microscopically positive [5]. Lymphocytic infiltration was observed within the tumor (Figure 1e) and at the tumor margins (Figure 1f). Further, we observed an abundance of blood vessels in the tumor (Figure 2a). Some megakaryocytes were also observed among the tumor cells (Figure $2 b$ ).
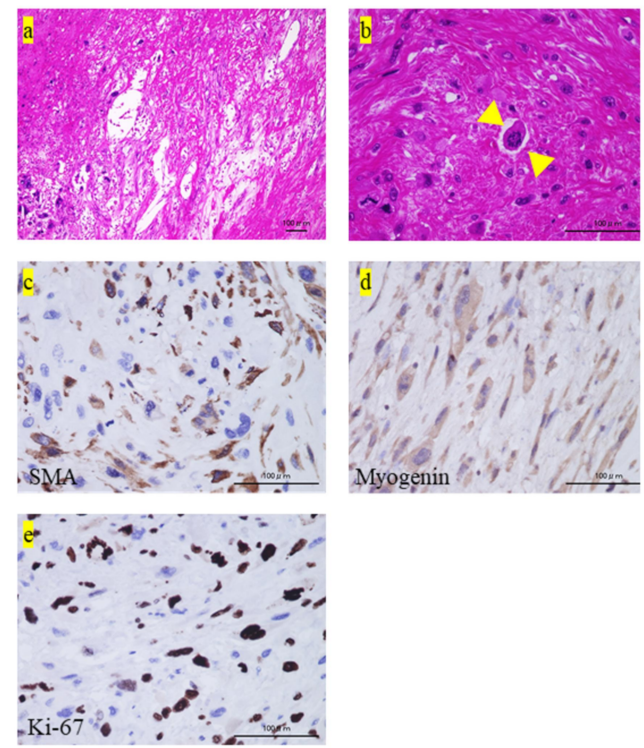

Figure 2. Pathological and iImmunohistochemical findings of the tumor. (a,b) The pathological findings of the excised specimen. The histology shows (a) increased vascular penetration into the tumor, (b) megakaryocytes (yellow arrowheads). (c-e) The immunohistochemical findings show positive staining for (c) smooth muscle antigen (SMA), (d) myogenin, (e), and Ki-67. IL, Interleukin.

Immunostaining was partially positive for smooth muscle antigen and slightly positive for myogenin (Figure 2c,d, respectively). The Ki-67 labeling index was approximately 50\% (Figure 2e). Immunostaining was negative for caldesmon, calponin, desmin, S-100, CD34, CD31, MDM2, and CDK4 (data not shown). The diagnosis of leiomyosarcoma was excluded because SMA was only partially positive, and desmin and HHF-35 were negative $[6,7]$. Furthermore, the diagnosis of rhabdomyosarcoma was excluded since myogenin was just slightly positive, and MyoD1, desmin, and HHF-35 were negative $[6,8]$. The diagnose of synovial sarcoma and malignant peripheral sheath tumor were also excluded because S-100 was negative [9]. Finally, we confirmed the diagnosis of UPS based on the histological findings of HE staining and these excluded diagnoses.

However, the immunostaining results were negative for CDK4, MDM2, CD31, CD34, S-100, desmin, AE1/AE3, Myf4, and calponin (data not shown). The inflammation markers of the blood improved a few days after the surgery (Figure 3); the patient's postoperative CRP level, white blood cell count, and neutrophil count were $0.305 \mathrm{mg} / \mathrm{dL}, 2.83 \times 10^{3} / \mu \mathrm{L}$, and $57.9 \%$, respectively. No recurrence was observed at one year after surgery. 

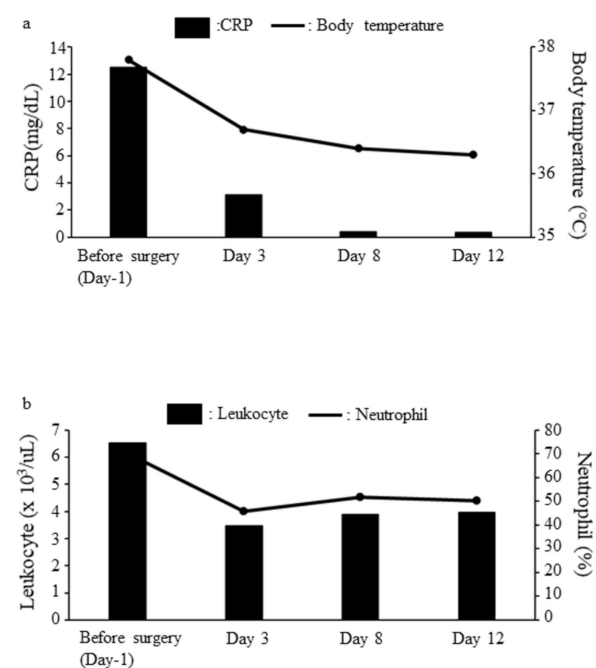

Figure 3. Pre- and post-operative comparison of inflammatory markers. (a) The pre- and postoperative progress chart of the CRP and body temperature. The black box shows CRP (mg/dL) and the black line shows body temperature $\left({ }^{\circ} \mathrm{C}\right)$. The CRP level and body temperature decrease and reach a normal value 3 days after surgery. (b) The pre- and post-operative progress chart of leukocytes $\left(\mathrm{x} 10^{3} / \mu \mathrm{L}\right)$ and neutrophils $(\%)$. The black box shows leukocytes $\left(\mathrm{x} 10^{3} / \mu \mathrm{L}\right)$, and the black line shows neutrophils (\%). The leukocytes and neutrophils decreased and become close to normal values 3 days after surgery. CRP, C-reactive protein.

\section{Discussion}

Inflammatory malignant fibrous histiocytoma (IMFH) is a rare neoplasm and was first reported in 1976 [10]. Approximately 22-65\% of MFH cases are CRP positive and show inflammatory infiltrates without infection, as previously described $[3,4,11]$. In the previously reported case series of 11 IMFH cases, positive CRP was not reported to be as high $(<1.0 \mathrm{mg} / \mathrm{dL})$ as in our case [3]. Recently, according to the WHO classification guidelines for STS, the MFH classification was eliminated in 2002 and was replaced with UPS [1]. Hayashida et al. reported that highly inflammatory UPS (IUPS) (CRP $=11.07 \mathrm{mg} / \mathrm{dL}$, leukocyte $=69,100 / \mu \mathrm{L}$ ) causes leukemoid reaction [4], and in the past, only one case of highly IMFH or IUPS was reported in the buttocks [12].

Over the last few years, major advances have been made in the characterization of the tumor microenvironment of soft tissue sarcoma, with the description of "hot tumors" massively infiltrated by immune cells and "cold tumors" with no significant immune infiltration [13]. Moreover, Petitprez, et al. established an immune-based classification on the basis of the composition of the tumor microenvironment and identified five distinct phenotypes: immune-low (A and B), immune-high (D and E), and highly vascularized (C) [13]. The report also indicated that the class-E group demonstrated improved survival and a high response rate to PD1 blockade with pembrolizumab in a phase 2 clinical trial [13]. In our case, blood vessels were abundant in the tumor, and lymphocytic infiltration was noted within the tumor, and at the tumor margins.

These findings suggested that the tumor was a "hot tumor," and there was a relationship between the tumor microenvironment and systemic inflammation. The current case could be further classified as immune-high (D and E), and/or highly vascularized (C) groups. Rapid growth and early metastasis have been observed in IUPS, and the involvement of G-CSF, IL-6, IL-7, IL-8, SCF, TGB, and G-CSF have also been suggested $[4,14,15]$. IL-6 is an important cytokine that plays various roles in many cells, such as proliferation of T lymphocytes, induction of B lymphocyte maturation, promotion of the growth of erythroid cells, myeloid cells, and megakaryocytes, and the induction of acute phase protein production by hepatocytes [16-18]. In this case, intratumoral infiltration of megakaryocytes and lymphocytes was observed. Thus, it was suggested that inflammatory cytokines might be acting on the tumor microenvironment. 
Diagnostic delays for STS have been reported previously and remain a huge issue that require better patient and doctor awareness [19]. Cancer diagnosis in the elderly is often delayed due to patient dementia [20]. In the current case, although the patient had no dementia, the diagnosis was delayed because the patient herself did not visit the clinic. However, the fever and the inflammatory reaction prompted her to visit the doctors, who were then able to find the sarcoma.

High uptake of FDG indicates higher tumor cellularity, biological behaviors of the tumor cells, and the composition and proportion of inflammatory cells [21]. Moreover, FDG uptake indicates marked leukocytosis in IUPS [4]. In the current case, although the patient showed a high level of inflammation, we observed a relatively low SUV-max; the mean SUV-max value, in general, is reported to be $10.78 \pm 6.72$, as described previously [22]. The heterogeneous FDG uptake suggested large necrotic areas.

The basic treatment for STS is wide-margin resection [1]. STS with inflammation or highly aggressive histology should be treated with neoadjuvant chemotherapy or radiation therapy $[23,24]$. However, neoadjuvant therapy is often difficult for the elderly because they have decreased immunity [25]. Therefore, an adequate wide margin should be acquired by surgery to obtain a favorable prognosis in such STS patients [26]. In the current case, although we planned to acquire wide-margin resection, the margin of the resected specimen was inadequate (R1) [5]. Despite inadequate surgical margins, additional radiation therapy and surgical resection were not performed because the patient and his family did not wish to undergo them. A previous study showed that pretreatment CRP or IL-6 levels are independent prognostic factors for STS [3,27]; however, whether old age is itself a prognostic factor is still controversial $[28,29]$. The STS recurrence generally occurs within the first two years after surgery [30]. Thus, careful follow-up is necessary in the future.

The present study had some limitations. First, the excluded diagnoses were due to the absence of an in-situ hybridization specific test for each tumor [31-33].

However, we were able to make a definitive diagnosis with HE staining and immunostaining.

In addition, we did not measure the blood levels of systemic inflammatory cyto-kines such as IL-6.

However, we were able to suggest the possibility of an association between tumor microenvironment and systemic inflammation from the histopathology. Moreover, we did not investigate several immune molecules, such as CD3, CD8, CD20, CD34, PD-1, and PD-L1, to confirm the immune-based classification [13]. If this tumor could have been classified as category E, PD-1 inhibitor therapy might have been indicated. This could be an interesting subject for future research.

\section{Conclusion}

In conclusion, we encountered a rare case of IUPS in a very elderly patient with high CRP. IUPS can be diagnostically confused with other infections, such as bacteremia, and even if there is no indication of bacteremia, blood cultures should be collected immediately to rule out infection. In addition, after ruling out such infections, prompt wide-margin resection should be performed to obtain a good patient prognosis.

Author Contributions: Conceptualization, K.H., S.N. and M.A.; methodology, K.H., S.N. and T.I.; software, K.H., T.I., N.O. and M.A.; validation, S.N., T.I., M.A. and N.O.; formal analysis, K.H., S.N. and N.O.; investigation, K.H., S.N., N.O., T.I. and M.A.; data curation, K.H., S.N., N.O., T.I. and M.A.; writing —original draft preparation, K.H., S.N., N.O. and M.A.; writing-review and editing, K.H., S.N., T.I., N.O. and M.A. All authors have read and agreed to the published version of the manuscript.

Funding: This research received no specific grant from any funding agency in the public, commercial, or not-for-profit sectors. 
Institutional Review Board Statement: This case report complies with the Declaration of Helsinki. This case study is also approved by Ethics Committee of Kindai University Hospital (Approved number: 31-253, Osaka, Japan).

Informed Consent Statement: The patient provided written informed consent for the publication of this information.

Data Availability Statement: The datasets used and/or analyzed during the current study are available from the corresponding author on reasonable request.

Acknowledgments: We would like to thank Editage (www.editage.jp) for English language editing.

Conflicts of Interest: We declare no conflicts of interest.

\section{References}

1. Fletcher, C.D.; Lazar, A.J. WHO classification of tumors of soft tissue and bone. In Soft Tissue and Bone Tumours, 5th ed.; IARC Publications: Lyon, France, 2020.

2. Weiss, S.W.; Enzinger, F.M. Malignant fibrous histiocytoma: an analysis of 200 cases. Cancer 1978, 41, 2250-2266. [CrossRef]

3. Nakamura, T.; Matsumine, A.; Matsubara, T.; Asanuma, K.; Uchida, A.; Sudo, A. Clinical significance of pretreatment serum C-reactive protein level in soft tissue sarcoma. Cancer 2012, 118, 1055-1061. [CrossRef] [PubMed]

4. Hayashida, K.; Kawabata, Y.; Kato, I.; Suzuki, M.; Takeyama, M.; Inaba, Y. G-CSF production by undifferentiated pleomorphic sarcoma with leukemoid reaction occurred in the lower leg: A case report. JBJS Case Connect. 2020, 10, e0624. [CrossRef]

5. Gundle, K.R.; Kafchinski, L.; Gupta, S.; Griffin, A.M.; Dickson, B.C.; Chung, P.W.; Catton, C.N.; O'Sullivan, B.; Wunder, J.S.; Ferguson, P.C. Analysis of margin classification systems for assessing the risk of local recurrence after soft tissue sarcoma resection. J. Clin. Oncol. 2018, 36, 704-709. [CrossRef]

6. Truong, L.D.; Rangdaeng, S.; Cagle, P.; Ro, J.Y.; Hawkins, H.; Font, R.L. The diagnostic utility of desmin. A study of 584 cases and review of the literature. Am. J. Clin. Pathol. 1990, 93, 305-314. [CrossRef]

7. de Saint Aubain Somerhausen, N.; Fletcher, C.D. Leiomyosarcoma of soft tissue in children: Clinicopathologic analysis of 20 cases. Am. J. Surg. Pathol. 1999, 23, 755-763. [CrossRef]

8. Dabbs, D.J.; Silverman, J.F.; Geisinger, K.R. Immunohistochemical study of uterine stromal sarcoma and rhabdomyosarcoma. Arch. Pathol. Lab. Med. 1989, 113, 1151-1154.

9. Smith, T.A.; Machen, S.K.; Fisher, C.; Goldblum, J.R. Usefulness of cytokeratin subsets for distinguishing monophasic syn-ovial sarcoma from malignant peripheral nerve sheath tumor. Am. J. Clin. Pathol. 1999, 112, 641-648. [CrossRef]

10. Kyriakos, M.; Kempson, R.L. Inflammatory fibrous histiocytoma. An aggressive and lethal lesion. Cancer 1976, 37, 1584-1606. [CrossRef]

11. Nakanishi, H.; Araki, N.; Kudawara, I.; Kuratsu, S.; Matsumine, A.; Mano, M.; Naka, N.; Myoui, A.; Ueda, T.; Yoshikawa, H. Clinical implications of serum C-reactive protein levels in malignant fibrous histiocytoma. Int. J. Cancer 2002, 99, 167-170. [CrossRef]

12. Hamada, T.; Komiya, S.; Hiraoka, K.; Zenmyo, M.; Morimatsu, M.; Inoue, A. IL-6 in a pleomorphic type of malignant fi-brous histiocytoma presenting high fever. Hum. Pathol. 1998, 29, 758-761. [CrossRef]

13. Petitprez, F.; de Reyniès, A.; Keung, E.Z.; Chen, T.W.; Sun, C.M.; Calderaro, J.; Jeng, Y.M.; Hsiao, L.P.; Lacroix, L.; Bougoüin, A.; et al. B cells are associated with survival and immunotherapy response in sarcoma. Nature 2020, 577, 556-560. [CrossRef] [PubMed]

14. Hurtado-Cordovi, J.; Avezbakiyev, B.; Frieri, M.; Freedman, L.; Gebre, W. Cutaneous inflammatory malignant fibrous histiocytoma presenting with a leukemoid reaction: A case report and review of the literature. Case Rep. Med. 2012, 798629. [CrossRef]

15. Hurtado-Cordovi, J.; Pathak, P.; Avezbakiyev, B.; Frieri, M. Inflammatory malignant fibrous histiocytoma associated with leukemoid reaction or leukocytosis: A comprehensive review. ISRN Oncol. 2012, 946019. [CrossRef] [PubMed]

16. Dillon, S.R.; Sprecher, C.; Hammond, A.; Bilsborough, J.; Rosenfeld-Franklin, M.; Presnell, S.R.; Haugen, H.S.; Maurer, M.; Harder, B.; Johnston, J.; et al. Interleukin 31, a cytokine produced by activated T cells, induces dermatitis in mice. Nat. Immunol. 2004, 5, 752-760. [CrossRef]

17. Derouet, D.; Rousseau, F.; Alfonsi, F.; Froger, J.; Hermann, J.; Barbier, F.; Perret, D.; Diveu, C.; Guillet, C.; Preisser, L.; et al. Neuropoietin, a new IL-6-related cytokine signaling through the ciliary neurotrophic factor receptor. Proc. Natl. Acad. Sci. USA 2004, 101, 4827-4832. [CrossRef]

18. Jones, S.A.; Richards, P.J.; Scheller, J.; Rose-John, S. IL-6 transsignaling: The in vivo consequences. J. Interferon. Cytokine Res. 2005, 25, 241-253. [CrossRef]

19. Brouns, F.; Stas, M.; De Wever, I. Delay in diagnosis of soft tissue sarcomas. Eur. J. Surg. Oncol. 2003, 29, 440-445. [CrossRef]

20. Iritani, S.; Tohgi, M.; Miyata, H.; Ohi, G. Impact of dementia on cancer discovery and pain. Psychogeriatrics 2011, 11, 6-13. [CrossRef] [PubMed]

21. Dong, A.; Wang, Y.; Dong, H.; Gong, J.; Cheng, C.; Zuo, C.; Lu, J. Inflammatory myofibroblastic tumor: FDG PET/CT findings with pathologic correlation. Clin. Nucl. Med. 2014, 39, 113-121. [CrossRef] 
22. Liu, D.N.; Li, Z.W.; Wang, H.Y.; Zhao, M.; Zhao, W.; Hao, C.Y. Use of 18F-FDG-PET/CT for Retroperitoneal/Intra-Abdominal Soft Tissue Sarcomas. Contrast Media Mol. Imaging. 2018, 2601281. [CrossRef]

23. Iwamoto, Y.; Tanaka, K.; Isu, K.; Kawai, A.; Tatezaki, S.; Ishii, T.; Kushida, K.; Beppu, Y.; Usui, M.; Tateishi, A.; et al. Multiinstitutional phase II study of neoadjuvant chemotherapy for osteosarcoma (NECO study) in Japan: NECO-93J and NECO-95J. J. Orthop. Sci. 2009, 14, 397-404. [CrossRef]

24. Larrier, N.A.; Czito, B.G.; Kirsch, D.G. Radiation therapy for soft tissue sarcoma: Indications and controversies for neo-adjuvant therapy, adjuvant therapy, intraoperative radiation therapy, and brachytherapy. Surg. Oncol. Clin. North Am. 2016, 25, 841-860. [CrossRef]

25. Weiskopf, D.; Weinberger, B.; Grubeck-Loebenstein, B. The aging of the immune system. Transpl. Int. 2009, 22, 1041-1050. [CrossRef]

26. Hashimoto, K.; Nishimura, S.; Hara, Y.; Oka, N.; Tanaka, H.; Iemura, S.; Akagi, M. Clinical outcomes of patients with primary malignant bone and soft tissue tumor aged 65 years or older. Exp. Ther. Med. 2019, 17, 888-894. [CrossRef] [PubMed]

27. Rutkowski, P.; Kaminska, J.; Kowalska, M.; Ruka, W.; Steffen, J. Cytokine serum levels in soft tissue sarcoma patients: Correlations with clinico-pathological features and prognosis. Int. J. Cancer 2002, 100, 463-471. [CrossRef] [PubMed]

28. Osaka, S.; Sugita, H.; Osaka, E.; Yoshida, Y.; Ryu, J. Surgical management of malignant soft tissue tumours in patients aged 65 years or older. J. Orthop. Surg. 2003, 11, 28-33. [CrossRef] [PubMed]

29. Yoneda, Y.; Kunisada, T.; Naka, N.; Nishida, Y.; Kawai, A.; Morii, T.; Takeda, K.; Hasei, J.; Yamakawa, Y.; Ozaki, T. Japanese Musculoskeletal Oncology Group Favorable outcome after complete resection in elderly soft tissue sarcoma pa-tients: Japanese musculoskeletal oncology group study. Eur. J. Surg. Oncol. 2014, 40, 49-54. [CrossRef]

30. Daigler, A.; Zmarsly, I.; Hirsch, T.; Goertz, O.; Steinau, H.U.; Lehnhardt, M.; Harati, K. Long-term outcome after local recurrence of soft tissue sarcoma: A retrospective analysis of factors predictive of survival in 135 patients with locally re-current soft tissue sarcoma. Br. J. Cancer 2014, 110, 1456-1464. [CrossRef] [PubMed]

31. Mitelman, F.; Johansson, B.; Mertens, F. The impact of translocations and gene fusions on cancer causation. Nat. Rev. Cancer 2007, 7, 233-245. [CrossRef]

32. Rubin, B.P.; Nishijo, K.; Chen, H.I.; Yi, X.; Schuetze, D.P.; Pal, R.; Prajapati, S.I.; Abraham, J.; Arenkiel, B.R.; Chen, Q.R.; et al. Evidence for an unanticipated relationship between undifferentiated pleomorphic sarcoma and embryonal rhabdomyosarcoma. Cancer Cell 2011, 19, 177-191. [CrossRef] [PubMed]

33. Kelleher, F.C.; Viterbo, A. Histologic and Genetic Advances in Refining the Diagnosis of "Undifferentiated Pleomorphic Sarcoma". Cancers 2013, 5, 218-233. [CrossRef] [PubMed] 